\title{
Design Mixers to Minimize Effects of Erosion and Corrosion Erosion
}

\author{
Julian Fasano, ${ }^{1}$ Eric E. Janz, ${ }^{2}$ and Kevin Myers ${ }^{3}$ \\ ${ }^{1}$ Mixer Engineering Co., 2673 Stonebridge Drive, Troy, OH 45373, USA \\ ${ }^{2}$ Chemineer, Inc., 5870 Poe Avenue, Dayton, OH 45414, USA \\ ${ }^{3}$ Department of Chemical \& Materials Engineering, University of Dayton, 300 College Park, Dayton, OH 45469-0246, USA
}

Correspondence should be addressed to Julian Fasano, j.fasano@mixerengineering.com

Received 29 September 2011; Accepted 8 January 2012

Academic Editor: Shunsuke Hashimoto

Copyright (C) 2012 Julian Fasano et al. This is an open access article distributed under the Creative Commons Attribution License, which permits unrestricted use, distribution, and reproduction in any medium, provided the original work is properly cited.

A thorough review of the major parameters that affect solid-liquid slurry wear on impellers and techniques for minimizing wear is presented. These major parameters include (i) chemical environment, (ii) hardness of solids, (iii) density of solids, (iv) percent solids, (v) shape of solids, (vi) fluid regime (turbulent, transitional, or laminar), (vii) hardness of the mixer's wetted parts, (viii) hydraulic efficiency of the impeller (kinetic energy dissipation rates near the impeller blades), (ix) impact velocity, and (x) impact frequency. Techniques for minimizing the wear on impellers cover the choice of impeller, size and speed of the impeller, alloy selection, and surface coating or coverings. An example is provided as well as an assessment of the approximate life improvement.

\section{Introduction}

There are numerous applications of mixers that deal with erosive solids, especially in the minerals processing and power industries. In many of these applications, there is an erosion-corrosion synergistic effect on the wear of a mixer's wetted parts, particularly the impeller. This paper pulls together the authors' research with numerous articles on erosion and erosion corrosion to permit a designer to optimize the cost-based life of eroding mixer parts before replacement is required.

There are a large number of factors that can affect the rate of erosion. Many of these factors have been known and studied to some extent:

(i) chemical environment,

(ii) hardness of solids,

(iii) density of solids,

(iv) difference in liquid and solid density,

(v) percent solids,

(vi) shape of solids,

(vii) fluid regime (turbulent, transitional, or laminar), (viii) fluid rheology (e.g., pseudoplasticity),

(ix) hardness of the mixer's wetted parts,

(x) young's modulus of the mixer's wetted parts,

(xi) hydraulic efficiency of the impeller (kinetic energy dissipation rates near the impeller blades),

(xii) impact velocity,

(xiii) impact frequency,

(xiv) angle of impact.

Theoretically the rate of volume loss of material is due to the kinetic energy lost when a particle impacts a material [1]. This would suggest a velocity exponent of 2 . However, presented below, experimental velocity exponents have ranged from 1.5 to 4.0. The general form of the equation relating erosion rate to velocity is given by

$$
E=K \cdot V^{n} f(\theta)
$$

where $E=$ volumetric erosion rate, $K=$ constant (function of all parameters other than $V$ or $\theta), V=$ particle velocity or relative velocity for rotating systems (impellers), $n=$ velocity 
exponent (can also be a function of other parameters), and $\theta=$ impingement angle.

Most investigators have used this general equation form.

Sapate and RamaRao [2] used a power law correlation between volumetric erosion rate and impingement velocity in a nonrotating system. They observed exponents on velocity of 1.91 to 2.52 . The velocity exponent showed an increasing trend with increasing hardness of the alloys irrespective of the hardness of the erodent particles and the impingement angle of the alloys investigated.

Stack [3] and others investigated the effect that corrosion plays in an erosion environment. These investigators studied various parameters of the corrosion-erosion environment in a nonrotating system. They observed velocity exponents that ranged from 1.4 to 3.5. They concluded that exponents derived for erosion of alloys under erosion-dominated conditions can be correlated to those derived for the strictly ductile erosion process. These are typically very near the theoretical "2" for the strictly ductile erosion process. However, those for the erosion corrosion dominated regime are higher than for the erosion-dominated regime and were in the 2.5 to 3.5 range. A publication by the Hydraulics Institute [4] suggests that the erosion velocity exponent for pumps in slurry transport is on the order of 2.5-3.0 .

Fort [5] and others studied pitched blade impellers $100 \mathrm{~mm}$ in diameter with a blade width of $20 \mathrm{~mm}$ in watersolid slurries under turbulent conditions. These impellers were studied at pitch angles of $20^{\circ}, 35^{\circ}$, and $45^{\circ}$. These studies included a slurry of $18.3 \%$ by volume of gypsum having a mean particle diameter of $0.1 \mathrm{~mm}$ and a $10 \%$ by volume slurry of $0.4 \mathrm{~mm}$ mean diameter sand particles. From their studies, they concluded the following.

(i) Particles of the lower hardness gypsum generated uniform sheet erosion over the entire surface of the impeller, while the particles of sand, having a higher hardness, generated predominately erosion of the leading edges of the impeller blade.

(ii) The higher the hardness of the blade material, the lower the wear rate of the blade.

(iii) The wear rate of the leading edge was not a function of pitch angle.

(iv) Sheet erosion of the blades exhibits a maximum erosion rate between $20^{\circ}$ and $45^{\circ}$.

Zheng [6] and others studied the erosion-corrosion synergistic effect in an acidic slurry. The slurry was $10 \%$ by weight $\mathrm{H}_{2} \mathrm{SO}_{4}$ and $15 \%$ by weight -60 mesh $(<0.251 \mathrm{~mm})$ corundum sand. Their apparatus was a rotating disk with four specimen holders on its edge. They determined the rate of erosion by making electrochemical measurements during rotation. All of their studies were done under turbulent flow conditions. Erosion rate velocity exponents ranged from 1.9 to 4.0. A model was proposed and used which divided the overall erosion rate into an erosion rate via corrosion, an erosion rate via erosion, and an erosion rate due to synergism. The synergism rate was very large and varied between 32 and 99\% of the total. The percent contributed by synergism diminished as the alloy became more statically corrosion resistant.

Amelyushkin and Agafonov [7] studied the erosion of cogeneration steam turbine blades caused by water droplets. If kinetic energy is high enough, even water droplets can cause erosion. They found that the toroidal and near root vortices were very intense and caused enhanced wear of the rotor blades. Also they found that they were able to eliminate erosion by making the water droplets small enough. It is expected that these effects are related to grain size. In ductile erosion, plastic deformation may occur first, before metal is removed. If erosion is due to intergranular grain fracture, then if particles are significantly smaller than the metal's grain size, erosion should be minimized. As ductile alloy grain sizes are on the order of $20 \mu \mathrm{m}$, particles smaller than this should have little erosive effect.

Khalid and Sapuan [8] studied wear for a centrifugal pump impeller in a slurry application. Weight and diameter losses were very nearly linear with time over 480 hours of operation. Blade height and depth loss did exhibit some nonlinearity but were modeled as linear. Typical of rotating devices in slurries, more material was lost near the periphery of the impeller than in the center because linear velocities increase with radial distance from the shaft.

López [9] and others studied the effect of corrosion erosion at relatively high velocities on 304 and 420 stainless steel. Velocities ranged from 4.5 to $8.5 \mathrm{~m} / \mathrm{s}$. Such velocities are not common in mixing equipment except in highshear devices. They used a rotating disc device with erosion samples attached to the periphery of the disc. The aqueous liquid for the slurry was composed of $70 \%$ by weight $\mathrm{H}_{2} \mathrm{SO}_{4}$ and $3.5 \% \mathrm{NaCl}$. The slurry solids were $30 \%$ by weight $\mathrm{SiO}_{2}$ particles with a mean diameter about $0.25 \mathrm{~mm}$. They found that high-velocity impacts were beneficial. The combined action of erosive and corrosive mechanisms did not lead to a significant increase in mass loss if compared to corrosion tests. They suggested that pores, small cracks, and fresh pits can be covered by the prows and lips that are formed as a consequence of the wedge action of round particles which produces a smoother, uniformly corroded surface. Thus, even though the transport mechanisms which remove corrosion products are greater due to higher velocities, the surface area exposed is smaller.

Corpstein and Fasano [10] studied slurry wear through multilayer paint modeling. The paint layers are on the order of $0.0381 \mathrm{~mm}$ thick. The three layers of paint used had an overall thickness of approximately $0.114 \mathrm{~mm}$. This is only about $7 \%$ of the blade thickness and did not change the fluid hydraulics over the blade. Erosion was studied using 8.3-inch diameter scaled down axial flow mixing impellers in a sand water slurry. These studies pointed out the strong effects that blade-shedding vortices, could have on erosive wear. Impellers, such as the four-bladed-pitched impeller that generated stronger vortices, suffered the highest degree of localized erosion. The effects of these vortices can completely wear through an impeller blade, leaving holes where the vortices contacted the surface. High-efficiency impeller blades created significantly smaller vortices and as a consequence exhibited much lower localized wear. Vortex 


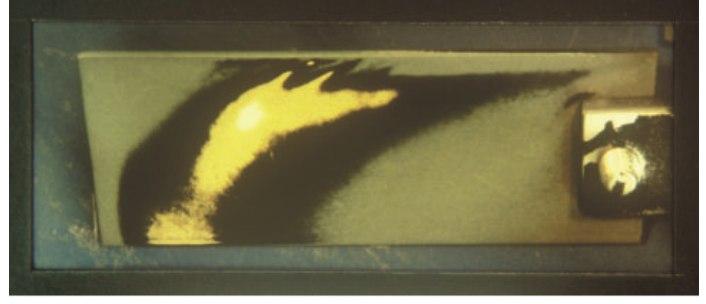

Figure 1: Backside of pitched blade impeller.

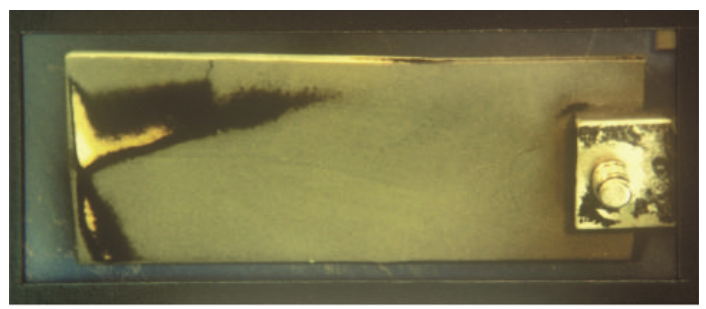

Figure 2: Backside of HE-3 high-efficiency impeller.

erosion can be severe and occurs on the backside (lowpressure side) of the impeller blade. Comparisons of the backside wear pattern for a Chemineer HE-3 impeller and a standard generic $45^{\circ}$ pitched four-bladed impeller are shown in Figures 1 and 2. The impellers were each $211 \mathrm{~mm}$ diameter and operated at $870 \mathrm{rpm}$ in a $10 \%$ by weight sand slurry in water. The weight mean particle size of the sand was $360 \mu \mathrm{m}$. These backside erosion patterns were made after only 30 minutes of operation, and it is obvious that the erosion on the backside of the $45^{\circ}$ four-bladed-pitched impeller was much more severe than the erosion for the Chemineer HE-3 high-efficiency impeller.

$\mathrm{Wu}$ [11] and others were also successful in using this technique to study five different style radial flow impellers and a low attack angle $\left(\sim 15^{\circ}\right)$ (6-bladed) pitched impeller. As expected, the hydraulically more efficient six-bladed-pitched impeller experienced the least erosion.

Increased hardness of metals will generally provide an increased life. Miller and Schmidt [12] compared the erosion rates of 16 metals in a recycled slurry test system using $2 \%$ by weight silica sand in water. The impeller tip velocity was $15.7 \mathrm{~m} / \mathrm{s}$, and the temperature was $16^{\circ} \mathrm{C}$. In addition to the erosion rate for each metal, they included the metal's hardness. The best fit for their data was logarithmic. However, probably due to the synergistic corrosion effects, the data was fairly dispersed. A plot of this data is provided in Figure 3. The effect of particle hardness depends on whether erosion is ductile or brittle. For brittle erosion, the effect of particle hardness is much more pronounced than for ductile erosion.

Changes in particle size can change the erosion mechanism. Stachowiak and Batchelor [13] reported that as the particle size was increased from $8.75 \mu \mathrm{m}$ to $127 \mu \mathrm{m}$, the mode of erosion changed from ductile to brittle. The erosion study

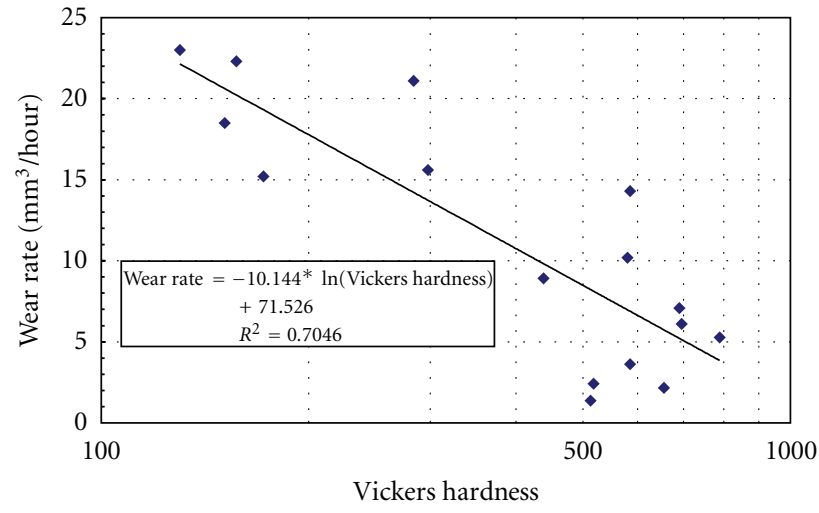

Figure 3: Wear rate data of Miller and Schmidt.

was for silicon carbide particles impinging on glass, steel, graphite, and ceramics. The particle velocity was $152 \mathrm{~m} / \mathrm{s}$.

\section{Design for Erosion Minimization}

Because maximum velocities in mixing processes seldom exceed $6 \mathrm{~m} / \mathrm{s}$, erosion and corrosion erosion of materials are fatigue processes for most mixing processes. There is generally not enough particle kinetic energy to cause ductile erosion where there is some plastic flow of material. The fatigue process occurs on a micro- or localized scale, and, as with macroscale fatigue, two stages of the erosion process have been observed. There is an incubation period followed by the formation and growth of pits involving the removal of the metal or material. Refer to a materials behavior text such as that by Armstrong and Zerilli [14] for a more in-depth discussion on material behavior.

Due to the vast number of parameters that can affect erosion or erosion-corrosion processes, and the fact that this area of mixer service has not been widely studied, it is very difficult to predict a priori what the rate of erosion will be for any given liquid-solid application. However, there are certain factors within the control of the designer that can be used to optimize the life of the mixer's wetted parts.

Most mixer designers will not have control over the type of slurry, the percent solids, the hardness of the solids, the shape of the solids, the liquid, the $\mathrm{pH}$, and so forth. However designers will generally have control over

(i) the mixer's wetted parts materials, coating, or lining,

(ii) the impeller style,

(iii) the impeller horsepower and speed combination.

2.1. Material Selection. The choice in selecting a material is to either go hard or soft and elastic. All else being equal, when selecting a metal alloy, a higher hardness will lead to a longer life. Thus, when selecting a metal alloy material, select a hard material which will also provide good corrosion resistance.

There are a number of hard surface ceramic coatings such as tungsten carbide or silicon carbide, which could be applied to the high-wear areas such as impeller blades. Ceramics are 
the most wear resistant but are low in toughness and impact strength. Ceramic coatings as well must be corrosion resistant to the liquid medium. Ceramics also do not have the ability to absorb much strain. These high strains on flexing blades may allow cracking of the ceramic coating. Ceramic coating applicators should be able to provide the maximum allowable strain for the ceramic coating under consideration. Coatings of the more common ceramic materials tend to be more costly than high-hardness metals, or elastomeric coverings [15].

Glass-lined equipment has a glass hardness of 5 to 6 on the Moh scale. For the great majority of solids, this hardness would be very acceptable. However, there are numerous materials and minerals including, $\mathrm{Al}_{2} \mathrm{O}_{3}, \mathrm{SiO}_{2}, \mathrm{WC}, \mathrm{SiC}$, and $\mathrm{ZiO}_{2}$ that have higher harnesses and would tend to wear away the glass lining. Glass linings have very many of the same limitations as ceramic coatings. They tend to be brittle and cannot tolerate much strain.

Elastomeric coverings on the order of $3 / 8^{\prime \prime}$ thick for industrial scale impellers have a long history of providing longer life in slurry applications. Instead of having to absorb most of the particle's impact energy, an elastomer releases most of the energy back to the particle after impact. Elastomeric lining manufacturers and applicators will generally recommend an elastomeric hardness of 40-60 Durometer A for optimum life. As with metals or hard surface coatings, the lining must also be compatible with the fluid medium. An elastomer's hardness is directly related to its corrosion resistance. However, as an elastomer's hardness increases above a 40 A Durometer, its erosion resistance decreases. A Durometer selection of 40-60 A is somewhat of a compromise between erosion and corrosion resistance. Elastomers should not be used when large particles are present. The term "large particles" is relative to the impinging velocity and mass of the particle, as well as the thickness of the elastomeric covering. If the impinging particle can bottom out against the metallic substrate, elastomeric coverings should not be used. Even if most of the slurry might be suitable, a small percentage of tramp particles can do significant damage to the elastomeric covering. Since impact energy is a function of the impingement angle, the leading edges of impeller blades are almost always double wrapped. The most popular elastomeric coverings are natural rubber, neoprene, butyl, chlorobutyl, and hypalon. Improperly applied linings on highefficiency impellers that significantly change the profile of the blade can cause increased erosion problems. Typically linings are double layered on the leading, trailing, and outside edges of impeller blades. These linings must be adequately feathered such that the transition from the double layer to the single layer is smooth to avoid generation of additional vortices.

Both thermoplastic and thermoset polymers do not have the ability to restore back to the particle most of the kinetic energy and are generally not as good in mixing slurry service. Hercules 1900 UHMWPE, touted as being a very abrasion-resistant polymer, was tested by the authors against polymeric protective coatings elastomers 2001-B (natural rubber Durometer A 30-40) and 1054-B (chlorobutyl rubber Durometer A 35-45). The testing procedure was identical to that specified in the Hercules 1900 UHMWPE bulletin. A
TABLE 1

\begin{tabular}{lc}
\hline Material & $\begin{array}{c}\text { Rate of weight loss, } \\
\mathrm{g} / \mathrm{hr}\end{array}$ \\
\hline $\begin{array}{l}\text { Hercules 1900 UHMWPE } \\
\text { Polymeric protective coatings 2001-B (natural } \\
\text { rubber) }\end{array}$ & 0.0975 \\
$\begin{array}{l}\text { Polymeric protective coatings 1054-B } \\
\text { (chlorobutyl) }\end{array}$ & 0.0104 \\
\hline
\end{tabular}

$50 \%$ sand-water slurry was used with a sand weight mean particle size of $53 \mu \mathrm{m}$. The specimen tip speed was $2.22 \mathrm{~m} / \mathrm{s}$. Weight loss was determined at various time intervals over an 8 -hour period. The weight loss versus time was found to be linear with $R^{2}$ values for all three falling between 0.93 and 0.94. The rates of erosion were shown in Table 1 .

As can be observed, the rate of weight loss for the thermoplastic polymer is 7 to 10 times greater than that for the elastomers tested.

Dickey and Fasano have provided a general reference on materials selection considerations [16].

2.2. Impeller Selection. There are many different impeller styles available to the designer. Selecting the correct impeller can often make a difference in impeller life of two or three times. Erosion of impeller blades can depend heavily on the flow regime, with flow regime being determined by the impeller Reynolds number

$$
N_{\mathrm{Re}}=\frac{\rho N D^{2}}{\mu},
$$

where $\rho=$ density, $N=$ impeller rotational speed, $D=\mathrm{im}$ peller diameter, $\mu=$ viscosity, and $N_{\mathrm{Re}}=$ Reynolds number, dimensionless.

Impellers in turbulent flow create shedding vortices that attach themselves to the back of impeller blades. There are a number of techniques that can be used to visualize these vortices. In Figures 4 and 5, telltales attached to the blade are used to visualize these vortices [17]. They are shown for both a relatively inefficient $45^{\circ}$ pitched four-blade impeller and the Chemineer HE-3 high-efficiency impeller.

In these figures, the impellers are rotating clockwise when viewed from above. Thus, the blades are moving into the page, and the view is of the backside of the blades. These vortices cause very localized wear emanating from the backside or low-pressure side of impeller blades. These impeller vortices begin to diminish at Reynolds numbers below 10,000 , become very weak below a Reynolds number of 500, and have completely disappeared below a Reynolds number of 10 . As most slurry particles are heavier than the fluid, the centrifugal effect caused by the vortex will cause particles caught in the vortex to migrate to the OD of the vortex. Thus, the concentration of solids at the periphery of the vortex is much higher, and the rate of solid particle to surface impacts is much greater, increasing locally the rate of erosion. Of course, particles must be small enough to be captured in 


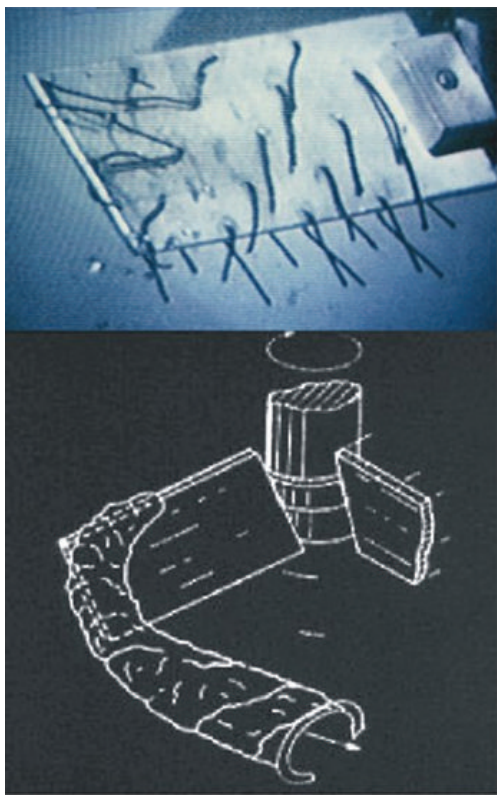

Figure 4: Pitched blade impeller vortex.

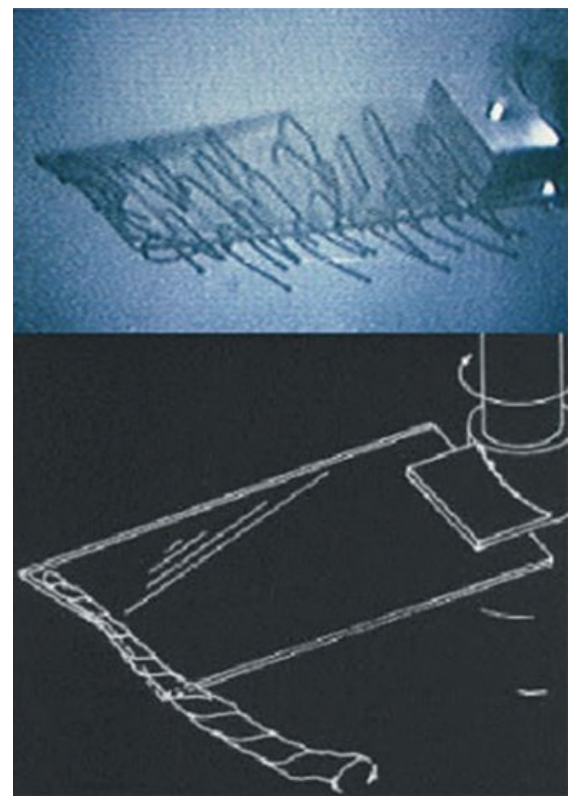

FIGURE 5: HE-3 impeller vortex.

these vortices before this effect would be observed. On an industrial scale, however, the greatest majority of slurry applications would have particles sufficiently small to be captured by these vortices.

There are a number of relatively efficient wide blade impellers used in solids suspension service. Fasano and Reeder [18] compared the erosion rate between a Chemineer Maxflo W impeller, Figure 6 , and a standard $45^{\circ}$ four-bladed-pitched impeller (refer to Figure 4).

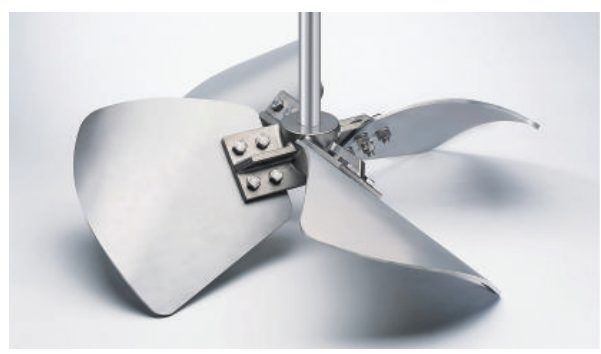

Figure 6: Chemineer Maxflo W impeller.

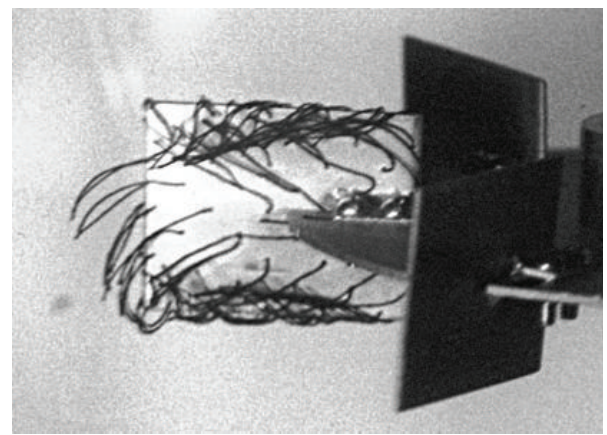

Figure 7: Telltales on D-6 impeller blade.

For the same level of solid suspension, these impellers utilize the same impeller diameter at the same speed. Therefore, velocities at the impeller are the same. The rate of erosion however for the pitched-blade impeller was, on a percentage basis, $59 \%$ greater than the erosion rate of the Maxflo W impeller.

Radial flow impellers are not very efficient in suspending solids. However, radial flow impellers are efficient in dispersing gasses. In applications where solids are present and a gas must be dispersed, they are often used. As with axial flow impellers, impeller efficiency changes with design. The Rushton or D-6 impeller, introduced in the late 1940s, creates a pair of vortices behind each blade in turbulent flow. These vortices, as we have observed with the pitched-blade impeller, can cause severe erosion from the backside of the blade. Figure 7 photo of the intertwined telltales on the backside of the blade demonstrates the size and nature of these vortices.

There exist today highly efficient radial flow impellers. The Chemineer CD-6 impeller was introduced into the marketplace in 1988, and the even more efficient Chemineer BT-6 was introduced in 1998. Both of these impellers exhibit very little tendency for vortex formation on the backside of the blade. This is demonstrated in telltale photos, in Figures 8 and 9. In each of these photos, the blades are rotating into the plane of the paper.

Under turbulent flow conditions, it is usually very beneficial, both from an erosion standpoint as well as a process efficiency standpoint, to select a high-efficiency style impeller. In transitional flow, there are still benefits to be achieved by the use of a high-efficiency impeller, but not as profound as in turbulent flow. In laminar flow, there is 
TABLE 2: Possible process design selections for example.

\begin{tabular}{|c|c|c|c|c|c|c|c|}
\hline $\begin{array}{l}\text { Impeller } \\
\text { diameter, m }\end{array}$ & $\begin{array}{l}\text { Impeller } \\
\text { dia./tank dia. }\end{array}$ & $\begin{array}{l}\text { Impeller } \\
\text { speed, rpm }\end{array}$ & $\begin{array}{l}\text { Impeller } \\
\text { power, kW }\end{array}$ & $\begin{array}{l}\text { Impeller } \\
\text { torque, } \mathrm{kNm}\end{array}$ & $\begin{array}{l}\text { Impeller } \\
\text { tip speed, } \mathrm{m} / \mathrm{min}\end{array}$ & $\begin{array}{l}\text { Relative } \\
\text { wear life* }\end{array}$ & $\begin{array}{l}\text { Approx. } \\
\text { relative cap. } \\
\text { cost }\end{array}$ \\
\hline 0.889 & 0.243 & 159 & 3.49 & 0.210 & 444 & 1.00 & 1.00 \\
\hline 1.016 & 0.278 & 123 & 2.94 & 0.228 & 392 & 1.54 & 1.06 \\
\hline 1.143 & 0.313 & 102 & 3.15 & 0.294 & 366 & 1.96 & 1.25 \\
\hline 1.220 & 0.347 & 92 & 3.59 & 0.372 & 367 & 1.95 & 1.45 \\
\hline 1.397 & 0.382 & 84 & 4.05 & 0.460 & 369 & 1.92 & 1.67 \\
\hline 1.524 & 0.417 & 75 & 4.61 & 0.587 & 359 & 2.10 & 1.95 \\
\hline 1.651 & 0.451 & 70 & 5.23 & 0.713 & 363 & 2.02 & 2.22 \\
\hline 1.778 & 0.486 & 67 & 6.32 & 0.972 & 374 & 1.82 & 2.71 \\
\hline 1.905 & 0.521 & 65 & 9.16 & 1.345 & 389 & 1.59 & 3.35 \\
\hline
\end{tabular}

${ }^{*}$ Relative wear based on assumed velocity exponent of 3.5 .

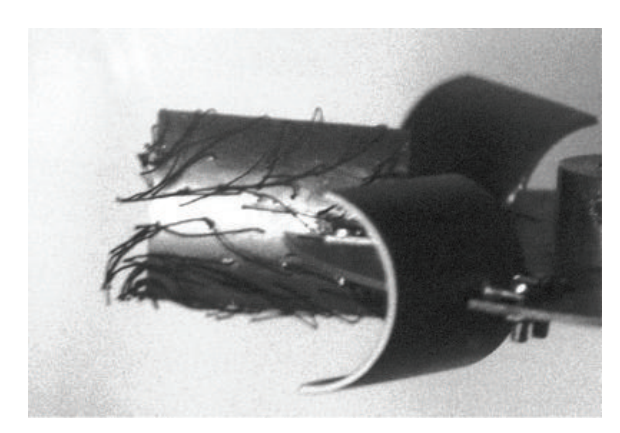

FIgure 8: Telltales on CD-6 impeller blade.

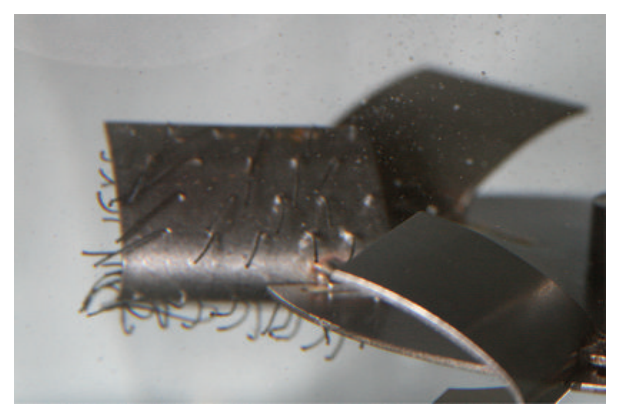

Figure 9: Telltales on BT-6 impeller blade.

no advantage in using a high-efficiency impeller either for erosion or solids suspension efficiency.

2.3. Horsepower and Speed Selection. As discussed earlier, erosion is very dependent on velocity, and typically in erosion-corrosion environments, the velocity exponent for the volumetric rate or weight rate of erosion is typically observed to be 2.5 to 4.0. In designing an agitator for the suspension of solids, the designer has a choice of selecting a number of power and speed combinations. Because solid suspension impeller efficiencies change with impeller style, impeller to tank diameter, and off-bottom clearance to tank diameter [19], a number of possible horsepower and speed choices can meet process objectives. The selection of a specific agitator design in the end should come down to economics. There are capital costs and operating costs. Capital costs are largely associated with the general size of the machine. The torque can generally best characterize the capital cost. Operating costs include the energy costs to operate the machine plus any maintenance costs. Maintenance costs include the costs of oil changes, new bearings, new gears, and new seal components, and in the case of erosion applications, the replacement of in-tank wear components, typically impeller blades. A close examination of the various horsepower and speed options should be examined closely in order to make an economic selection.

2.3.1. Example. For the sake of demonstration, let us assume that we need to design an agitator for suspending a $10 \%$ solution of sand in water. The sand will be assumed to have a weight mean particle size of $360 \mu \mathrm{m}$. The tank is $3.66 \mathrm{~m}$ diameter with a $2: 1$ elliptical dished bottom, and the watersand slurry will have a liquid volume such that the depth of liquid in the tank is $3.66 \mathrm{~m}$. The sand will be assumed to have a specific gravity of 2.4 and the water a specific gravity of 1.0. The viscosity of water will be assumed to be $1 \mathrm{mPa}$-s. The process solution requires that the solids be suspended to the "just suspended" condition such that no particles settle on the bottom of the tank for more than 2 seconds. All designs are to utilize a single HE-3 impeller onethird the tank diameter off-bottom. The horsepower, speed, and impeller diameter combinations that satisfy the process objective can be determined using solids suspension design procedures such as the article presented by Corpstein and others [19]. The following designs shown in Table 2 below all satisfy the off-bottom solids suspension process requirement.

Even though using small impellers operating at high speeds reduces capital costs and power, the high tip speeds of these designs lead to short wear lives. Using an intermediate size impeller that minimizes tip speed at the cost of higher capital and power costs maximizes the wear life. As can be observed, the torque and consequently the capital cost 
TABLE 3: Comparison of equal suspension to equal tip speed.

\begin{tabular}{lccc}
\hline Condition & $\begin{array}{c}\text { Impeller dia., } \\
\mathrm{cm}\end{array}$ & $\begin{array}{c}\text { Impeller speed, } \\
\text { rpm }\end{array}$ & $\begin{array}{c}\text { Impeller tip } \\
\text { speed, } \mathrm{m} / \mathrm{min}\end{array}$ \\
\hline Full scale design, 144 in. dia. tank & 139.7 & 84 & 369 \\
Scale-down design based on equal suspension & 17.46 & 456 & 250 \\
Scale-down design based on equal tip speed & 17.46 & 672 & 369 \\
\hline
\end{tabular}

increase dramatically with impeller to tank diameter ratios greater than 0.45 due to changes in the flow pattern generated by the impeller.

2.4. Scale-Down Studies. Since there is often an erosioncorrosion synergistic effect that cannot be predicted a priori with today's current data, any material selection should be studied on a smaller scale, before making a final choice. Since it is important to model the same hydraulic behavior over the blade, the authors recommend that the ratio of mean particle diameter to impeller diameter not exceed 0.008. For example, a mean particle diameter of $1 \mathrm{~mm}$ would suggest a small-scale impeller no less than $125 \mathrm{~mm}$ (4.9 in) diameter. It is also important to ensure that fluid regimes have not changed. If the impeller operation is turbulent on the large scale, it should also be turbulent on the small scale.

An optimum agitator horsepower and speed selection can be made as described above for the full scale. However, in order to determine the rate of erosion, scale-down studies should be made. A geometric scale-down for an equal level of solid suspension will result in a tip speed that will always be lower on the smaller scale, except when scaling down geometrically for very slow settling solids $(<0.1 \mathrm{~m} / \mathrm{min})$. Wear rate, as previously demonstrated, is a strong function of velocity. Therefore, all scale-down tests should be made at equal tip speed. As an example, if we examine the $1.397 \mathrm{~m}$ impeller solution for the above described problem and scale this down to a $0.4572 \mathrm{~m}$ diameter tank, we would have the comparison provided in Table 3 .

\section{Conclusions and Summary}

The rate of erosion is dependent on the following major static environmental factors: chemical environment, hardness of the solid particles, density of the solid particles, percent solids, the shape of the solids, the size of the solids including whether or not tramp solids are present, and type of impeller. The dynamic factors affecting erosion rate are fluid regime, impact velocity, impact frequency, and angle of impact. As there are no good means currently of predicting erosion rate, small-scale studies should be conducted emulating as much of the total environment as possible. These small-scale studies should be conducted using equal tip speed to mimic the full-scale rate of erosion.

Erosion in most mixing processes is a fatigue process normally accelerated by a liquid corrosive environment. The fatigue process occurs on a micro- or localized scale, and, as with macroscale fatigue, two stages of the erosion process have been observed. There is an incubation period followed by the formation and growth of pits involving the removal of the metal or material. One of two routes is generally utilized in dealing with an erosion application. The highvelocity areas such as the blades are either made from hard materials or coated with hard ceramic materials such as tungsten carbide or silicon carbide. Alternatively, the blades are covered with some type of elastomeric covering.

Impeller selection is important especially in turbulent flow conditions. High-efficiency impellers will generally erode at a slower rate because the backside of the blades has minimized shedding vortices. In laminar flow, from an erosion standpoint, most impellers behave similarly due to a lack of vortices. Thus, the selection of the impeller should be based primarily on what is required to accomplish the desired process result.

A number of horsepower and speed selections that satisfy the process requirement should be examined to conduct an economic analysis. The lowest possible speed may not be the most economical. It is best to first design the most cost optimum agitator for the full scale. Then in order to estimate the corrosion rate, scale down on the basis of equal tip speed.

\section{References}

[1] R. Chattopadhyay, Surface Wear, Analysis, Treatment and Prevention, ASM International, Metals Park, Ohio, USA, 2001.

[2] S. G. Sapate and A. V. RamaRao, "Effect of erodent particle hardness on velocity exponent in erosion of steels and cast irons," Materials and Manufacturing Processes, vol. 18, no. 5, pp. 783-802, 2003.

[3] M. M. Stack, F. H. Stott, and G. C. Wood, "The significance of velocity exponents in identifying erosion-corrosion mechanisms," Journal de Physique IV, Colloque C9, Supplement au Journal de Physique III, vol. 3, 1993.

[4] A New Slurry Pump Standard, Pumps and Systems, The Hydraulic Institute, 2006.

[5] I. Fort, J. Medek, and F. Ambros, "Erosion wear of axial flow impellers in a solid-liquid suspension," Acta Polytechnica, vol. 41, no. 1, pp. 23-28, 2001.

[6] Y. Zheng, Z. Yao, X. Wei, and W. Ke, "The synergistic effect between erosion and corrosion in acidic slurry medium," Wear, vol. 186-187, no. 2, pp. 555-561, 1995.

[7] V. N. Amelyushkin and B. N. Agafonov, "Special features of erosion wear of rotor blades of cogeneration steam turbines," Power Technology and Engineering, vol. 36, no. 6, pp. 359-362, 2002.

[8] Y. A. Khalid and S. M. Sapuan, "Wear analysis of centrifugal slurry pump impellers," Industrial Lubrication and Tribology, vol. 59, no. 1, pp. 18-28, 2007.

[9] D. López, J. P. Congote, J. R. Cano, A. Toro, and A. P. Tschiptschin, "Effect of particle velocity and impact angle on 
the corrosion-erosion of AISI 304 and AISI 420 stainless steels," Wear, vol. 259, no. 1-6, pp. 118-124, 2005.

[10] R. C. Corpstein and J. B. Fasano, "Erosion of rubber covered impeller blades in an abrasive service," The Indian Chemical Engineer, vol. 36, no. 1, 1990.

[11] J. Wu, B. Ngyuen, L. Graham, Y. Zhu, T. Kilpatrick, and J. Davis, "Minimizing impeller slurry wear through multilayer paint modelling," Canadian Journal of Chemical Engineering, vol. 83, no. 5, pp. 835-842, 2005.

[12] J. E. Miller and F. Schmidt, Slurry Erosion: Uses, Applications and Test Methods, ASTM, 1987.

[13] G. W. Stachowiak and A. W. Batchelor, Engineering Tribology, Butterworth-Heinemann, 3rd edition, 2005.

[14] R. W. Armstrong and F. J. Zerilli, "Dislocation mechanics based viscoplasticity description of FCC, BCC and HCP metal deformation and fracturing behaviors," in Proceedings of ASME International Mechanical Congress and Exposition, pp. 417-428, November 1995.

[15] K. C. Wilson, G. R. Addie, A. Sellgren, and R. Clift, Slurry Transport Using Centrifugal Pumps, Springer, 2nd edition, 2005.

[16] D. S. Dickey and J. B. Fasano, Handbook of Industrial Mixing, chapter 21, section 9, John Wiley and Sons, New Jersey, NJ, USA, 2004, Edited By Paul, Atiemo-Obeng and Kresta.

[17] J. B. Fasano, "Flow visualization techniques on rotating impellers," in Proceedings of the Engineering Foundation Mixing Conference XII, Pitosi, MO, USA, 1989.

[18] J. B. Fasano and M. F. Reeder, "An improved maxflo impeller," in Proceedings of the North American Mixing Forum, Mixing Conference XVII, Banff, Canada, August 1999, Paper 2.4.

[19] K. J. Myers, R. R. Corpstein, A. Bakker, and J. B. Fasano, "Solid suspension agitator design with pitched blade and high efficiency impellers," in Proceedings of the AIChE Annual Meeting, St. Louis, MO, USA, November 1993. 

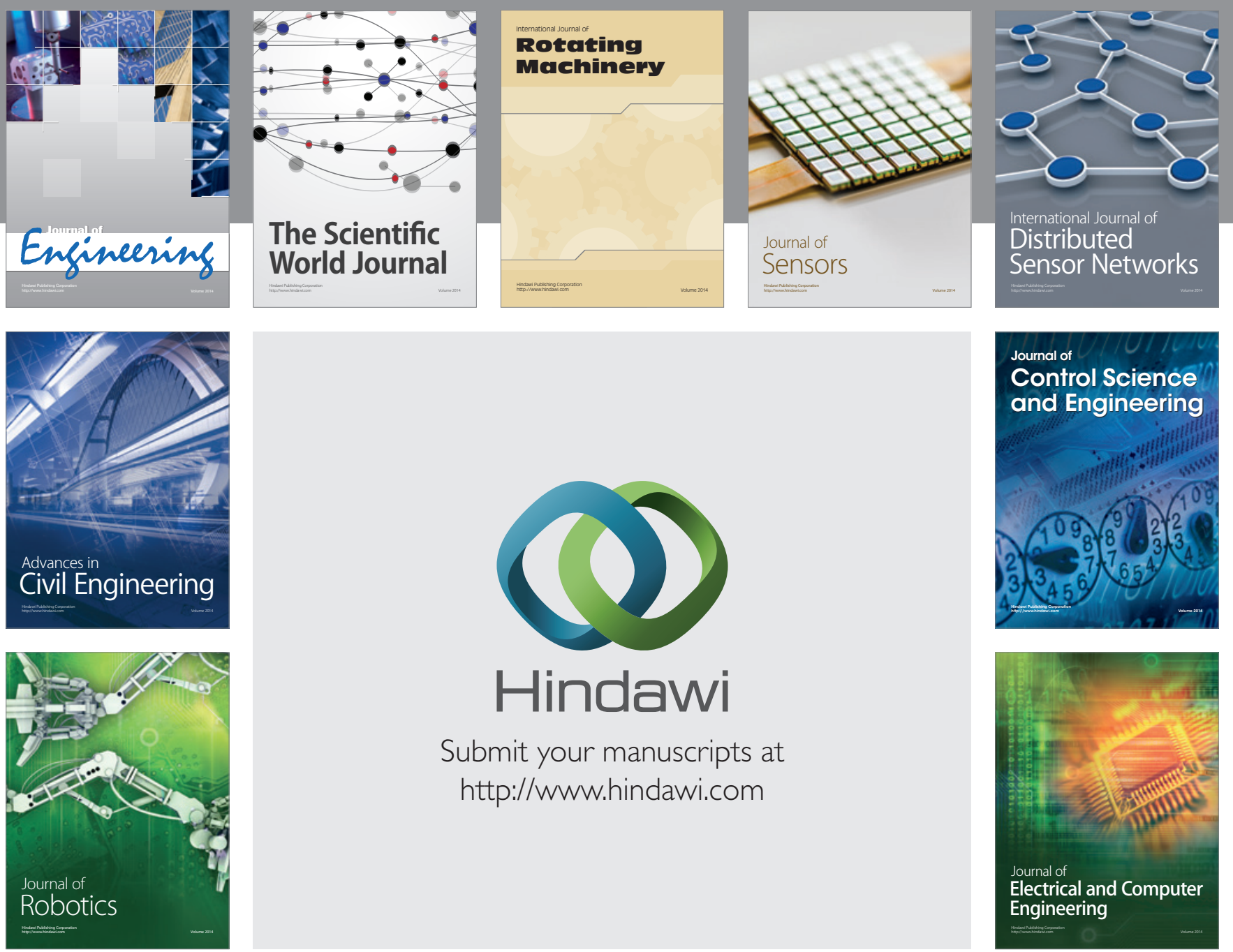

Submit your manuscripts at

http://www.hindawi.com
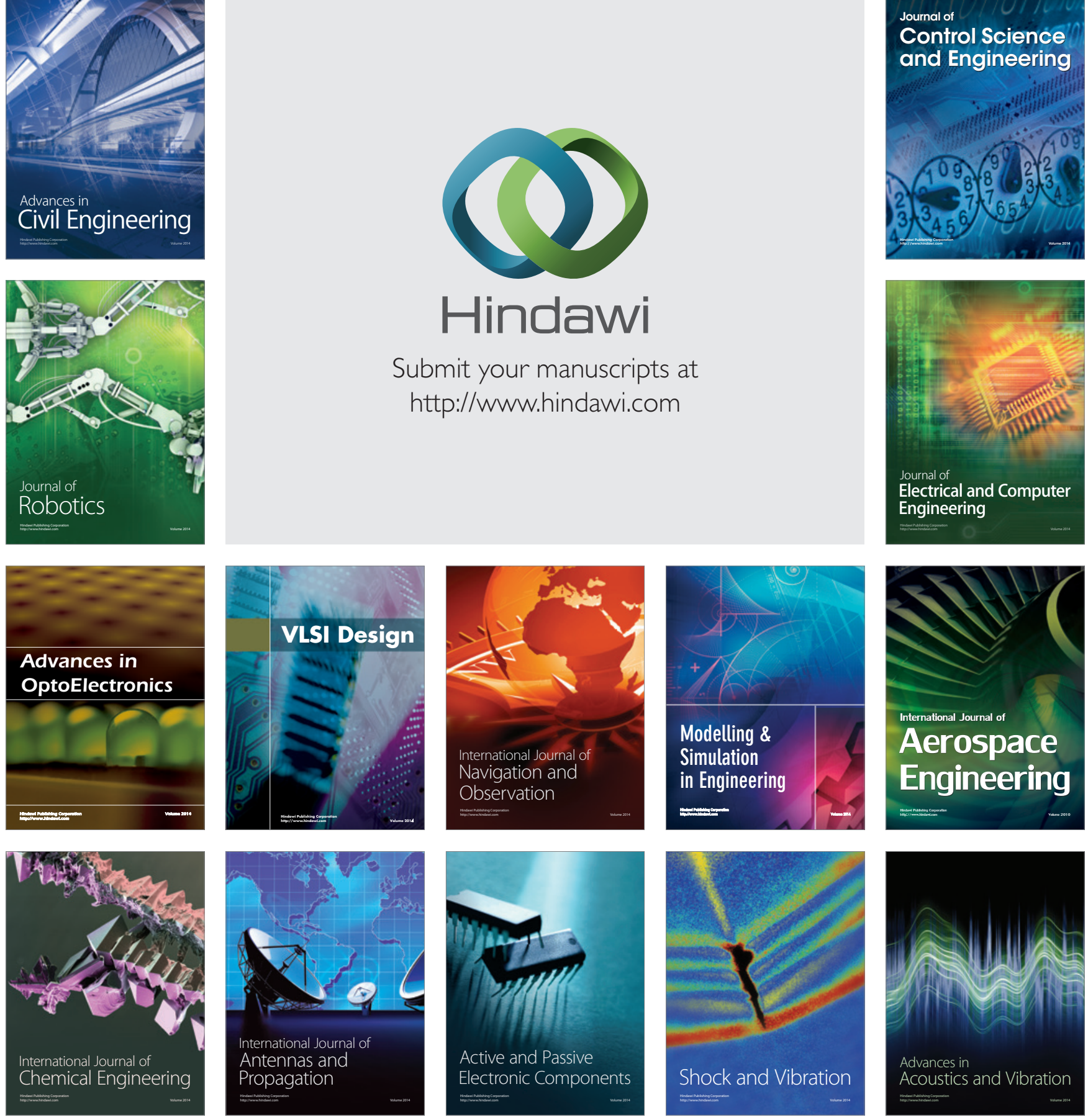